\title{
TERRITORIALIZAÇÃO DO PROGRAMA NACIONAL DE PRODUÇÃO E USO DE BIODIESEL E CONCENTRAÇÃO DE CAPITAL NO BRASIL
}

\section{TERRITORIALIZATION OF THE NATIONAL PROGRAM FOR BIODIESEL PRODUCTION AND USE AND CAPITAL ACCUMULATION IN BRAZIL}

\section{TERRITORIALIZACIÓN DEL PROGRAMA NACIONAL DE PRODUCCIÓN Y USO DE BIODIESEL Y CONCENTRACIÓN DE CAPITAL EN BRASIL}

\author{
José Antônio Lobo dos Santos \\ Universidade Federal da Bahia \\ Júlio César Suzuki \\ Universidade de São Paulo
}

\begin{abstract}
Resumo: A implantação do Programa Nacional de Produção e Uso de Biodiesel (PNPB) no Brasil possui implicações na produção do espaço. Assim, buscamos compreender como o PNPB vem se territorializando a luz de um amplo processo de concentração de capital, com significado na criação de infraestruturas produtivas de forma concentrada, num mercado capitalista extremamente oligopolizado com amplo processo de expropriação da renda da terra camponesa. Os resultados das análises mostraram que grandes grupos econômicos estão controlando o processo produtivo de biodiesel no país, assim como o mercado e a produção de matérias-primas. Esse controle, na prática, vem se evidenciando num conjunto de estratégias do capital voltadas para concentração de riquezas, a exploração de trabalho e a territorialização dos interesses corporativos na produção de energia com utilização de oleaginosas no Brasil.
\end{abstract}

Palavras-chaves: PNPB, exploração de trabalho, renda da terra camponesa, estabelecimento rural, concentração de capital.

Abstract: The implementation of the National Program for Biodiesel Production and Use (PNPB) in Brazil has implications for the production of space. Thus, we sought to understand how PNPB has been territorializing to the light of a broad process of capital accumulation, meaning the creation of productive infrastructure in concentrated form, in a capitalist market extremely oligopolistic, with a wide process of expropriation of peasant land rent. The analysis results showed that large conglomerates are controlling the biodiesel production process, as well as marketing and production of raw materials. In practice, this control has become clear by a set of capital strategies focused on wealth concentration, labor exploitation and the territorialization of corporate interests in energy production using oil seeds in Brazil.

Keywords: PNPB, labor exploitation, peasant land rent, rural properties, capital accumulation. 
Resumen: La implementación del Programa Nacional de Producción y Uso de Biodiesel (PNPB) en Brasil tiene implicaciones en la producción del espacio. Por lo tanto, tratamos de entender cómo el PNPB ha sido territorializado en relación al amplio proceso de concentración de capital, con significado en la creación de infraestructuras produtivas en forma concentrada en un mercado extremadamente olipolizado con amplio proceso de expropiación de la renta de la tierra campesina. Los resultados del análisis mostraran que grandes grupos económicos están controlando el proceso productivo de biodiesel en el país, así como el mercado y la producción de materias primas. Este control, en la práctica, ha venido mostrando un conjunto de estratégias del capital dirigidas a la concentracción de riquezas, explotación del trabajo $y$ territorialización de los intereses corporativos en la producción de energia con el uso de semillas oleaginosas en Brasil.

Palabras clave: PNPB, explotación del trabajo, renta de la tierra campesina, propiedad rural, concentración del capital.

\section{Introdução}

É relevante salientar que boa parte das novas fontes energéticas que estão sendo desenvolvidas na atualidade, a exemplo da produção de biodiesel no Brasil, está sendo pensada como complemento ao petróleo e não como fonte energética alternativa. A lógica que fundamenta a produção do biodiesel no Brasil é a utilização do mesmo adicionado ao petróleo, como complemento, que garante a continuidade da utilização deste combustível fóssil e não como elemento que se coloca como um novo caminho à utilização do petróleo.

Além da possibilidade de escassez dos tradicionais recursos energéticos, outra vertente importante que permeia o discurso de legitimação da produção de biodiesel é o debate que envolve as questões ambientais, em que as mudanças climáticas estão sendo colocadas como um dos principais desafios para a humanidade no século XXI. A preocupação específica com relação ao clima diz respeito ao aquecimento global que é, em parte, gerado pelo excesso de emissão de gás carbônico na atmosfera, havendo um entendimento de que grande parte desse excesso deriva do modelo energético atual, cuja matriz básica de matéria-prima está calcada nos combustíveis fosseis ${ }^{1}$.

Em um contexto que vai desde a subordinação de determinados países aos ditames dos agentes hegemônicos que controlam o mercado global do petróleo até os

\footnotetext{
${ }^{1}$ Cabe, aqui, mencionar que há leituras distoantes em relação às mudanças climáticas, para as quais se evidenciam os ritmos da Natureza como fundamental para a compreensão das dinâmicas climáticas, sendo ainda salientada a insuficiência de informação para distinguir o que é resultado da sociedade humana e o que é efeito dos rearranjos da Natureza.
} 
desafios das consequências do processo identificado como de aceleração do aquecimento global, assim como da necessidade de se buscar novos instrumentos para o próprio aprofundamento da acumulação e reprodução do capitalismo, o Brasil cria, no ano de 2004, o Programa Nacional de Produção e Uso do Biodiesel (PNPB).

O PNPB é um programa interministerial do Governo Federal que objetiva a implementação de forma sustentável, tanto técnica, como econômica, da produção e uso do biodiesel, com enfoque na inclusão social e no desenvolvimento regional, via geração de emprego e renda. Os documentos oficiais do Governo federal atestam que a principal diretriz do Programa é implantar um modelo de energia sustentável, a partir da produção e uso do biodiesel obtido de diversas fontes oleaginosas, que promova a inclusão social, garantindo preços competitivos, produto de qualidade e abastecimento (MCT, 2005: 1).

Acompanhando uma tendência mundial e a necessidade do modo capitalista de produção de desenvolver novas formas de reprodução, os projetos para produção e uso do biodiesel ganham força e, com isso, entram, do ponto de vista institucional, nas prioridades do Governo brasileiro nos últimos anos. Em janeiro de 2005, foi publicada a Lei Federal de no 11.097 que estabeleceu, para o período entre os anos de 2008 e 2013, a obrigatoriedade da adição de uma porcentagem de 2\% (B2) de biodiesel ao óleo diesel comercializado em todo o país, sendo que, no ano de 2010, o percentual obrigatório passou para 5\% (B5). Essa medida criou oficialmente o mercado do biodiesel e estabeleceu uma nova etapa na utilização de energia oriunda da biomassa no Brasil.

Com a criação de um marco regulatório e o estabelecimento de metas para o desenvolvimento do Programa, o Brasil passou a despontar no cenário mundial como uma possível potência na produção das chamadas energias renováveis oriundas da biomassa. Essa condição colocou o país em posição estratégica no cenário mundial no que compete ao controle de fontes energéticas, o que poderá abrir novas oportunidades de crescimento econômico, possibilitando ao capital atuar e se reproduzir de forma direta em áreas onde antes não eram tão interessantes.

Diante dos meandros que envolvem a produção nacional de biodiesel, evidenciase a relevância da análise do processo de implantação do Programa Nacional de Produção e Uso de Biodiesel no Brasil e suas implicações na produção do espaço. Para tanto, buscamos, como objetivo geral, compreender como o PNPB vem se territorializando a luz de um amplo processo de concentração de capital. 
Neste artigo, buscamos ampliar as discussões voltadas para o debate do contexto de criação e construção cotidiana do PNPB e com isso avaliar suas implicações práticas, ou seja, seus efeitos no processo de desenvolvimento do país, dando destaque à concentração da produção, à oligopolização do mercado e ao processo de expropriação da renda da terra camponesa, pois uma parte significativa da matéria-prima para a produção de biodiesel é produzida pela agricultura camponesa. Diante dessa realidade, entendemos ser de suma importância identificar e compreender as estratégias que norteiam, na atualidade, as políticas governamentais voltadas para a criação de novas fontes de energia no bojo do processo de criação e implantação do PNPB.

Para tanto, o artigo está dividido em quatro momentos. No primeiro, apresentamos, de forma introdutória, algumas considerações sobre a criação do PNPB e sua implantação no Brasil. No segundo, discutimos a respeito do processo de territorialização do Programa no país e a concentração da produção em determinadas regiões e Estados. No terceiro momento, abordamos questões relacionadas à atuação de grupos hegemônicos controlando o mercado e a infraestrutura produtiva de biodiesel. Por fim, tercemos considerações a respeito das implicações que a implantação do Programa vem apresentando nos últimos anos.

\section{Implantação do PNPB e o processo de concentração da produção}

O Biodiesel é um tipo de combustível produzido a partir de fontes naturais como óleos vegetais e as gorduras animais. Ele é obtido por meio da reação com álcool e catalisadores (transesterificação) ou com a destilação com catalisadores (craqueamento) e pode ser utilizado em qualquer motor a diesel de caminhões, ônibus, barcos, trens, máquinas agrícolas e até em motores que geram energia elétrica, conforme Edgardo Aquiles Prado, Renato André Zan, Deisy Camila Golfetto e Vânia Denise Schwade:

\section{A legislação brasileira define biodiesel como um derivado de um mono-alquil éster de ácidos graxos de cadeia longa, proveniente de fontes renováveis como óleos vegetais ou gordura animal, cuja utilização está associada à substituição de combustíveis fósseis em motores de ignição por compressão (motores do ciclo Diesel). (EDGAR; ZAN; GOLFETTO; SCHWADE, 2006: 9.208).}

O biodiesel pode ser usado puro ou misturado ao diesel em diversas proporções. A mistura de biodiesel ao diesel de petróleo, no caso em vigor de 5\%, é chamada de B5, referente à percentagem de agregação do biodiesel ao diesel derivado do petróleo, passando de B5 até o biodiesel puro, o qual é denominado B100. A mistura do biodiesel 
e também do etanol, respectivamente ao diesel e à gasolina, tem a vantagem do aproveitamento de um arranjo produtivo já existente na agricultura capitalista (lida como agronegócio), conforme defendem alguns autores.

A mudança gradual da atual matriz energética para a próxima é, também, um fator de sucesso na implementação dos biocombustíveis, comparados às outras alternativas energéticas, como nuclear, fotovoltaica, eólica ou via hidrogênio. A possibilidade de usar arranjos já disponíveis para geração, distribuição e consumo evita a necessidade de pesados investimentos prévios à adoção do novo combustível.

Assim, adição de etanol à gasolina e de biodiesel ao diesel de petróleo (petrodiesel), que vem sendo feita pioneiramente no Brasil há poucos anos, usa a capacidade instalada do agronegócio da cana e das oleaginosas e permite prever um crescente aumento da necessária evolução tecnológica para lidar com essas substâncias. (EDGAR; ZAN; GOLFETTO; SCHWADE, 2006: 9.207).

Segundo o discurso oficial do MDA (2008), além de ser um combustível limpo, que não polui o ambiente, a produção industrial do biodiesel e o cultivo de matériasprimas vão ajudar a criar milhares de empregos na agricultura camponesa, estimulando a inclusão social, principalmente nas regiões Norte e Nordeste e na área do Semi-árido brasileiro. Além disso, o biodiesel vai fazer com que o Brasil importe menos diesel de petróleo, gerando uma grande economia para a nação.

Outra questão está relacionada ao próprio marco regulatório do Programa, que prevê estabelecimento de contrato de "parceria" entre agricultores camponeses e as empresas processadoras de matéria-prima. Essa iniciativa, da forma com está sendo proposta, é diferente e contraditória, principalmente quando se trata de agentes historicamente antagônicos, como é o caso dos camponeses e dos empresários das agroindústrias. Um mecanismo chamado de Selo Combustível Social ${ }^{2}$ é colocado como o instrumento viabilizador das contraditórias relações que estão sendo construídas dentro do PNPB. No sentido de legitimar ideologicamente essas ações, o Governo Federal estabelece que:

\footnotetext{
${ }^{2}$ O Selo Combustível Social foi criado com o objetivo de estabelecer regras e determinados mecanismos para viabilizar um conjunto de relações entre empresas processadoras de biodiesel e os camponeses produtores de matérias-primas. O referido Selo foi criado pelo Decreto 5.297 de 06 de dezembro de 2004, o qual traz em seu artigo $2^{\circ}$ a seguinte redação: "Art. $2^{\circ}$ Fica instituído o selo "Combustível Social", que será concedido ao produtor de biodiesel que: I - promover a inclusão social dos agricultores familiares enquadrados no Programa Nacional de Fortalecimento da Agricultura Familiar - PRONAF, que lhe forneçam matéria-prima; e II - comprovar regularidade perante o Sistema de Cadastramento Unificado de Fornecedores - SICAF. [...]".
} 
O uso autorizativo do biodiesel no início de sua comercialização, o regime tributário diferenciado reconhecendo a importância da produção de oleaginosas pela agricultura familiar - principalmente de mamona e dendê nas regiões Norte, Nordeste e no Semi-árido - e a criação do Selo Combustível Social são instrumentos do marco regulatório para promover a inclusão social na cadeia de produção do novo combustível. O Selo, concedido pelo Ministério de Desenvolvimento Agrário (MDA), estabelece as condições para os produtores industriais de biodiesel obterem benefícios tributários e financiamentos. Para receber o Selo, o produtor industrial terá que adquirir matéria-prima de agricultores familiares, além de estabelecer contrato com especificação de renda e prazo e garantir assistência e capacitação técnica. (CARTILHA BIODIESEL, 2008, p. 08)

Em seu formato legal, o Selo Combustível Social se configura numa exigência institucional, presente no marco regulatório que visa criar garantias à participação da agricultura camponesa na produção de matérias-primas para a produção de biodiesel. $\mathrm{O}$ Selo vincula benefícios de financiamentos, tributários e de compra da matéria-prima, com preços pré-estabelecidos, de modo a tentar oferecer alguma segurança comercial aos camponeses e permitir certa organização ao setor de comercialização das matériasprimas. O Selo Combustível Social permite às empresas produtoras de biodiesel melhores condições de financiamento junto ao Banco Nacional de Desenvolvimento Econômico e Social (BNDES), além de garantir a participação dessas empresas nos leilões de compra do biodiesel, realizados pela Agência Nacional do Petróleo, Gás Natural e Biocombustíveis (ANP).

A implantação do PNPB, no Brasil, a partir do ano de 2005, criou um novo marco de intervenção estatal, por meio de políticas públicas de governo, na geração de combustíveis a partir da biomassa. Esse novo marco se fundamenta em duas frentes:

- A primeira, é o novo papel que o Estado assume em viabilizar a infraestrutura básica para a ampliação da capacidade produtiva do país no setor de biocombustíveis, via financiamento da produção, isenções fiscais, pesquisas e rede de distribuição e comercialização para o biodiesel produzido a partir de variadas espécies de oleaginosas, sobretudo nas regiões Norte e Nordeste do país.

- A segunda, é a participação de forma direta do Governo Federal no mercado de biocombustíveis, uma vez que o Governo estabeleceu um conjunto de normatizações para a comercialização e consumo do produto, entre outras formas, determinando percentuais de adição de biodiesel na gasolina e no óleo diesel. 
Quadro 1 - Brasil: evolução dos biocombustíveis entre 1973 e 2011

\begin{tabular}{|c|c|}
\hline 1973 & Primeiro choque do petróleo \\
\hline 1975 & Brasil cria o Proálcool \\
\hline 1977 & Adição de 4,5\% de etanol à gasolina \\
\hline 1979 & Adição de $15 \%$ de etanol à gasolina \\
\hline 1980 & Segundo choque do petróleo \\
\hline 1983 & Carros a etanol representam $90 \%$ do total de vendas \\
\hline 1985 & Percentual de etanol adicionado à gasolina chega a $22 \%$ \\
\hline 1989 & Preços do petróleo caem e gasolina se equipara ao etanol \\
\hline 1990 & Etanol passa a representar de $20 \%$ a $25 \%$ da gasolina \\
\hline 2003 & Lançamento dos carros biocombustíveis \\
\hline 2005 & É lançado o programa nacional de Biodiesel \\
\hline 2007 & Terceiro choque do petróleo \\
\hline 2008 & Início da obrigatoriedade do B2 \\
\hline abril/2008 & Consumo do etanol se equipara ao da gasolina \\
\hline janeiro/2010 & Vigência do B5 \\
\hline abril/2011 & $\begin{array}{c}\text { ANP passa a regular e fiscalizar a produção de etanol, agora considerado um } \\
\text { combustível. Percentual na gasolina pode ir de } 18 \% \text { a } 25 \% \text { e é determinado } \\
\text { pelo governo }\end{array}$ \\
\hline
\end{tabular}

Fonte: Organizado por SANTOS, J. A. Lobo, com base nas informações da ANP 2012.

A materialização de políticas públicas específicas para o setor de produção de biocombustíveis vem proporcionando, ao longo dos anos, um processo de territorialização do biocombustível como mercadoria no sistema produtivo e no mercado nacional. Desde a década de 1970, com o Proálcool, até os dias atuais, com o PNPB, o Governo federal vem buscando estabelecer políticas com o objetivo de aumentar a produção e a oferta nacional de biocombustíveis. Uma síntese dessas ações no processo histórico pode ser observada no quadro 1.

As informações delineadas no quadro 1 mostram que, desde os anos de 1970, o Estado vem fazendo intervenções, por meio de políticas públicas, no sentido de contornar crises ligadas à oferta e ao consumo de petróleo no mercado mundial e também oferecer determinados tipos de combustíveis oriundos da biomassa ao mercado. No Brasil, uma das políticas de grande impacto foi a criação do Proálcool em 1975. Esse programa nasceu com o objetivo de intensificar a produção de álcool combustível, hoje chamado oficialmente de etanol ${ }^{3}$, aumentar a produção de safras agroenergéticas e a capacidade industrial de transformação visando a obtenção de álcool para a substituição da gasolina.

\footnotetext{
${ }^{3}$ A mudança do nome do combustível de álcool para etanol se deveu à normalização internacional. No Brasil a mudança foi concretizada por meio da Resolução $n^{\circ} 39$ da ANP, a qual foi publicada no Diário Oficial da União em 11 de dezembro de 2009.
} 
Com o Proálcool, o Governo visava, além de buscar substituir, em parte, o consumo da gasolina, atender aos anseios dos usineiros que buscavam se livrar das dívidas e abrir novos mercados para os derivados da cana-de-açúcar no país, assim como a voracidade dos grandes especuladores internacionais em abrir novos mercados e ampliar os já existentes para a comercialização de equipamentos e insumos industriais, como mostram Bray, Ferreira e Ruas (2000:57) afirmando que:

Entretanto, com a criação do Proálcool, o Estado Nacional vai resolver: $1^{\circ}$ o problema do usineiro - com dívidas via Fundo Especial de Exportação e $2^{\circ}$ a questão dos fabricantes de equipamentos industriais do ramo que tinham se estruturado para fazer frente ao Programa de Racionalização da Agroindústria Açucareira/Álcooleira.

O que fica evidente é que por trás do Proálcool existiam outros interesses que buscavam acolher os anseios de grandes usineiros e indústrias fornecedoras de equipamentos para as usinas e insumos em maiores quantidades que atendessem a produção do álcool combustível e a expansão das lavouras de cana-de-açúcar. Essa receita vai contribuir ao longo dos anos para aprofundar a concentração da terra e a expansão da monocultura no país.

Outro elemento que vale a pena chamar a atenção é o poderio político e econômico que tanto no auge quanto na crise do Proálcool vai se concentrar nas mãos dos usineiros, pois esses vão se organizar para formarem um mercado extremamente oligopolizado no que se refere à produção, distribuição e comercialização de álcool no país, ou seja, são novos fluxos de capital sob rígido controle de um poderoso grupo comandado por grandes usineiros no país.

Em linhas gerais, o Proálcool se dividiu em três fases. A primeira foi o momento de implantação do programa entre os anos de 1975 e 1979. Nesse intervalo, o programa tinha uma ambiciosa meta de produzir 3,0 bilhões de litros de álcool. Segundo Bray, Ferreira e Ruas (2000:57) “essa fase vai do surgimento do Proálcool até o denominado 'segundo choque do petróleo', destacando a sua implementação como solução para a crise do açúcar no mercado mundial e como um programa de alternativa energética". Na concretização do programa, foi estabelecida uma nova meta de produzir 10,7 bilhões de litros de álcool, o que no período (1980 a 1985) representava 170 mil barris de petróleo/dia, tendo em vista que "nesta fase o Proálcool assumiu a postura de um programa que ia além de uma mera alternativa energética, isto é, caracterizava-se como 
um plano que visava, principalmente a substituição da gasolina" (BRAY; FERREIRA; RUAS, 2000:58).

Em sua terceira fase, a partir de 1986, o Proálcool passou por reestruturações, principalmente na parte de liberação de recursos públicos para financiamento da produção e instalação de novas destilarias. Além disso, fontes diversas relacionam a crise estrutural do programa ao processo de recuperação do preço do açúcar no mercado internacional, o que provocou o deslocamento de parte da matéria-prima (cana-deaçúcar) para a produção de açúcar e não necessariamente de álcool. Destacamos, também, nesse período, a queda no preço internacional do petróleo, o que tornou o álcool combustível pouco vantajoso tanto para o consumidor quanto para o produtor.

Por força da redução dos subsídios governamentais, da concorrência com o açúcar e com o petróleo, o álcool começou a ficar escasso nos postos de combustíveis do país, situação que contribuiu para acirrar ainda mais a crise no setor, causando grandes transtornos para os milhões de motoristas que adquiriram carro movido a álcool entre as décadas de 1970 e 1990. O resultado desse conjunto de problemas foi a total descrença no Proálcool por parte dos consumidores, das montadoras de automóveis, dos usineiros e do próprio Governo.

Os consumidores passaram a rejeitar os carros movidos a álcool e optar pelos veículos movidos à gasolina e as montadoras praticamente abandonaram a produção de carro movido a álcool. Já os usineiros deslocaram a produção do álcool para o açúcar, já que esta possibilitava maiores ganhos no mercado internacional e consequentemente maiores possibilidades de ampliação de capital.

Com esses ingredientes, o Proálcool, como modelo de substituição da gasolina, sofreu profundos impactos e com isso deixou pelo caminho muitos prejuízos para milhões de pessoas que compraram veículos movidos a álcool e depois sofreram com a desvalorização do bem e de outros problemas relacionados. Elias (2011:13) descreve bem parte desses problemas quando relata que: 
Efetivamente, os programas e projetos inerentes à produção de agrocombustíveis a partir da cana-de-açúcar são emblemáticos para tentarmos melhor entender um pouco do que vem ocorrendo hoje com esta nova febre dos agrocombustíveis, incluindo o biodiesel. Parece importante destacar que, apesar de todo sucesso tecnológico a partir do Proálcool, ele foi responsável por um dos mais significativos processos de concentração econômica, de concentração da terra, de expulsão de milhares de pequenos agricultores que não conseguiram permanecer no campo, por inúmeros e complexos impactos ambientais, entre tantas outras mazelas.

O resultado da avaliação dos obstáculos existentes no Proálcool é que o PNPB não deve enveredar pelos mesmos caminhos do Proálcool, que surgiu para a substituição, em larga escala, dos combustíveis veiculares derivados de petróleo por álcool, financiado pelo governo do Brasil, a partir de 1975, devido às crises do petróleo de 1973 e 1979. Esse programa tinha a cana-de-açúcar como principal matéria-prima, produzida em grandes extensões de terras (latifúndios), com degradantes condições de trabalho, cuja produção era altamente controlada pelo grande capital nacional (usineiros) e internacional (empresas multinacionais), como mostram Abramovay e Magalhães (2007:01/02) afirmando que:

A importância da cana-de-açúcar, a força dos interesses nacionais e, cada vez mais, internacionais ligados a sua expansão parecem confirmar a previsão feita recentemente na prestigiosa revista Foreign Affairs por dois professores da Universidade da Minesotta [...] de que a história da demanda industrial por produtos agrícolas nos países em desenvolvimento beneficia fundamentalmente os maiores produtores.

O Brasil precisa avançar na construção de alternativas energéticas que possam garantir autonomia frente aos agentes que controlam o mercado das atuais fontes e ao próprio petróleo como combustível fóssil altamente poluidor. “[...] o Brasil não deve ficar atrelado ao petróleo, isso significa nosso suicídio. O petróleo foi ingrediente fundamental da montagem da dívida externa [...]" (VASCONCELLOS; VIDAL, 2004:20). No entanto, salientamos que, atualmente, com a ampliação da capacidade tecnológica de extração de petróleo da Petrobrás e com o início da exploração de petróleo na camada Pré-sal estamos menos dependentes das oscilações internacionais no abastecimento e no preço do barril de petróleo. Porém, entende-se que as possíveis alternativas energéticas devem estar atreladas ao compromisso com a inclusão social 
das camadas empobrecidas da população com base numa ótica que foque e dê prioridade ao desenvolvimento social.

A soberania energética é fundamental, pois "a alienação energética é doença crônica, fruto da desvinculação do homem brasileiro de sua realidade espaço-temporal e que resulta da mente colonial da classe dirigente". (VASCONCELLOS; VIDAL, 2004:21). Há uma necessidade de se avançar na busca da inclusão social, no que compete à geração de energia e que ao mesmo tempo possa garantir a geração de renda para a população, sobretudo aos menos favorecidos no país. Mas será que o PNPB, enquanto política pública, tem essas características? Será que a participação da agricultura camponesa na cadeia produtiva do Programa vai contribuir para incluir esses trabalhadores de forma soberana e participativa nessa nova urdidura produtiva do capital?

O Estado deve buscar atuar de forma ativa e sintonizada com as prioridades nacionais, sobretudo na garantia da soberania energética e democratização do acesso à renda. As políticas públicas desenvolvidas pelo Estado devem ser ativas e focadas no desenvolvimento social, porém, como nos mostra Elias (2011:15):

[...] a ação do Estado se dá também de maneira passiva, especialmente quando deixa de intervir, por exemplo, para a não consolidação dos processos de concentração econômica e da terra já visíveis também a partir da produção de biodiesel. Dessa forma, já se pode perceber que continua a dar um amplo amparo para os setores econômicos considerados competitivos, para atuar no biodiesel.

Esse amplo amparo concedido pelo Estado, para que determinados setores hegemônicos da economia possam participar efetivamente do PNPB, é verificado quando observamos que a soja, como monocultura produzida em grandes propriedades e com alto índice de modernização técnica, vem predominando como principal matériaprima na produção nacional de biodiesel, conforme podemos conferir na figura 1 . 


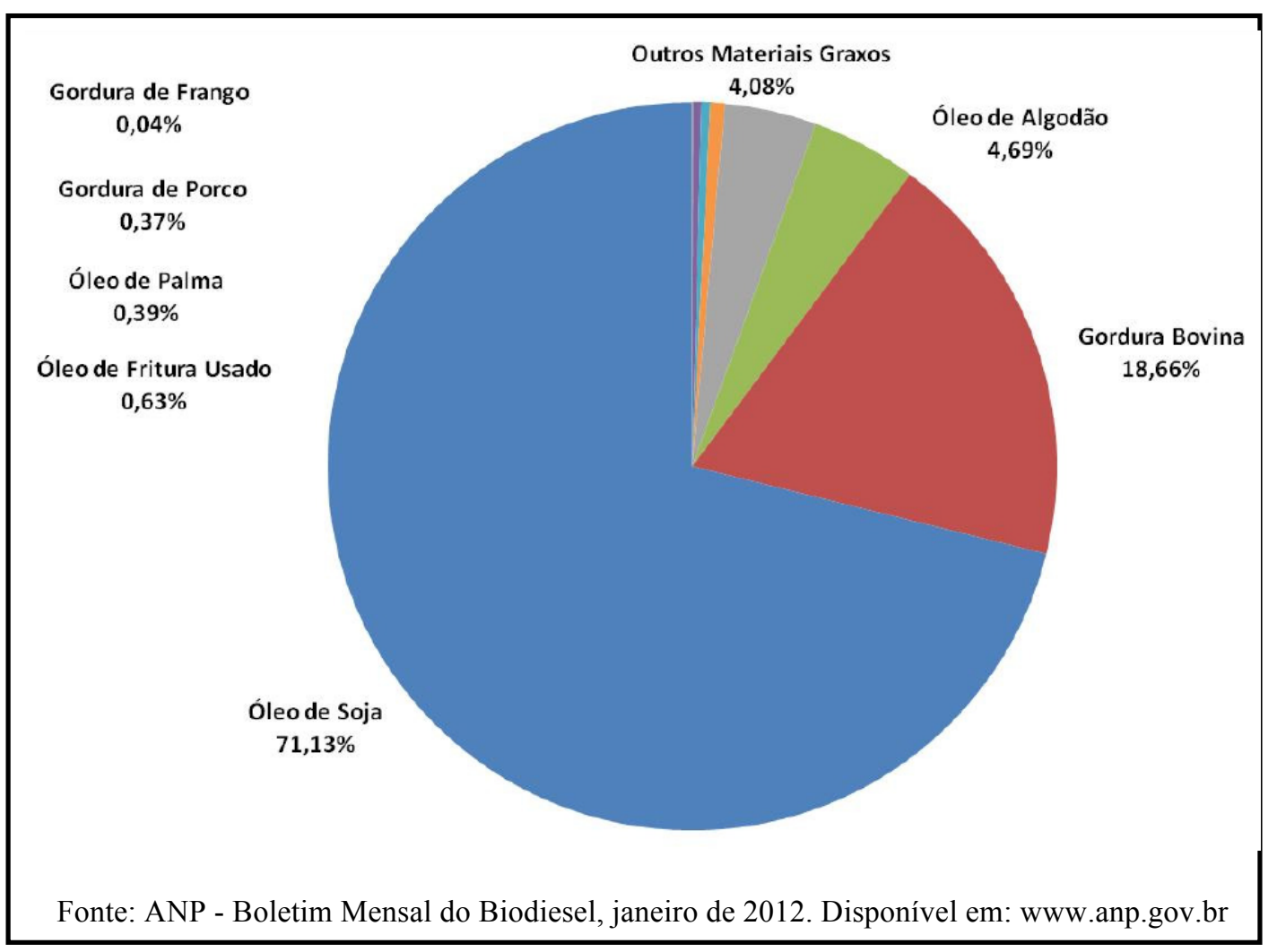

Figura 1 - Brasil: matérias - primas utilizadas para a produção de biodiesel, dezembro de 2011

Pelos dados oficiais da própria ANP, constatamos que o grosso da produção de biodiesel atualmente no Brasil tem a soja como matéria-prima principal (71,13\%), o que representa quase dois terços de todo o biodiesel produzido atualmente. A gordura bovina responde por $18,66 \%$ e o óleo de algodão, que também tem origem na agricultura capitalista, responde por 4,69\%. Juntos, esses três produtos (soja, algodão e gordura bovina), são responsáveis por $94,48 \%$ de toda produção de biodiesel no país. Diante dessa realidade, questionamos: cadê a participação do campesinato? Cadê a eficiência do Selo Combustível Social? Cadê a participação das oleaginosas oriundas das regiões Norte e Nordeste do Brasil, visto que a palma, que aparece nos dados da figura 1 , representa apenas $0,39 \%$ do biocombustível produzido e a mamona nem aparece?

São questionamentos difíceis de responder, pois as possíveis respostas refletem os dilemas e as contradições de um Programa gerado no seio do modo capitalista de produção com roupagem e discurso de programa social includente. Nesse modelo organizacional, o campesinato fica espremido e confinado na condição de um simplório fornecedor de matérias-primas em quantidades complementares, pois o produto básico 
para a produção do biodiesel está sendo ofertado pelos agentes hegemônicos da agricultura capitalista brasileira, o que, de certa forma, tende a crescer nos próximos anos, pois a capacidade nominal acumulada (capacidade instala e autorizada pela ANP para produção de biodiesel), a demanda compulsória (produção obrigatória para adição de biodiesel ao óleo diesel comercializado no país) e a produção anual de biodiesel vêm apresentando relativo crescimento nos últimos anos no Brasil, como demonstra a figura 2.

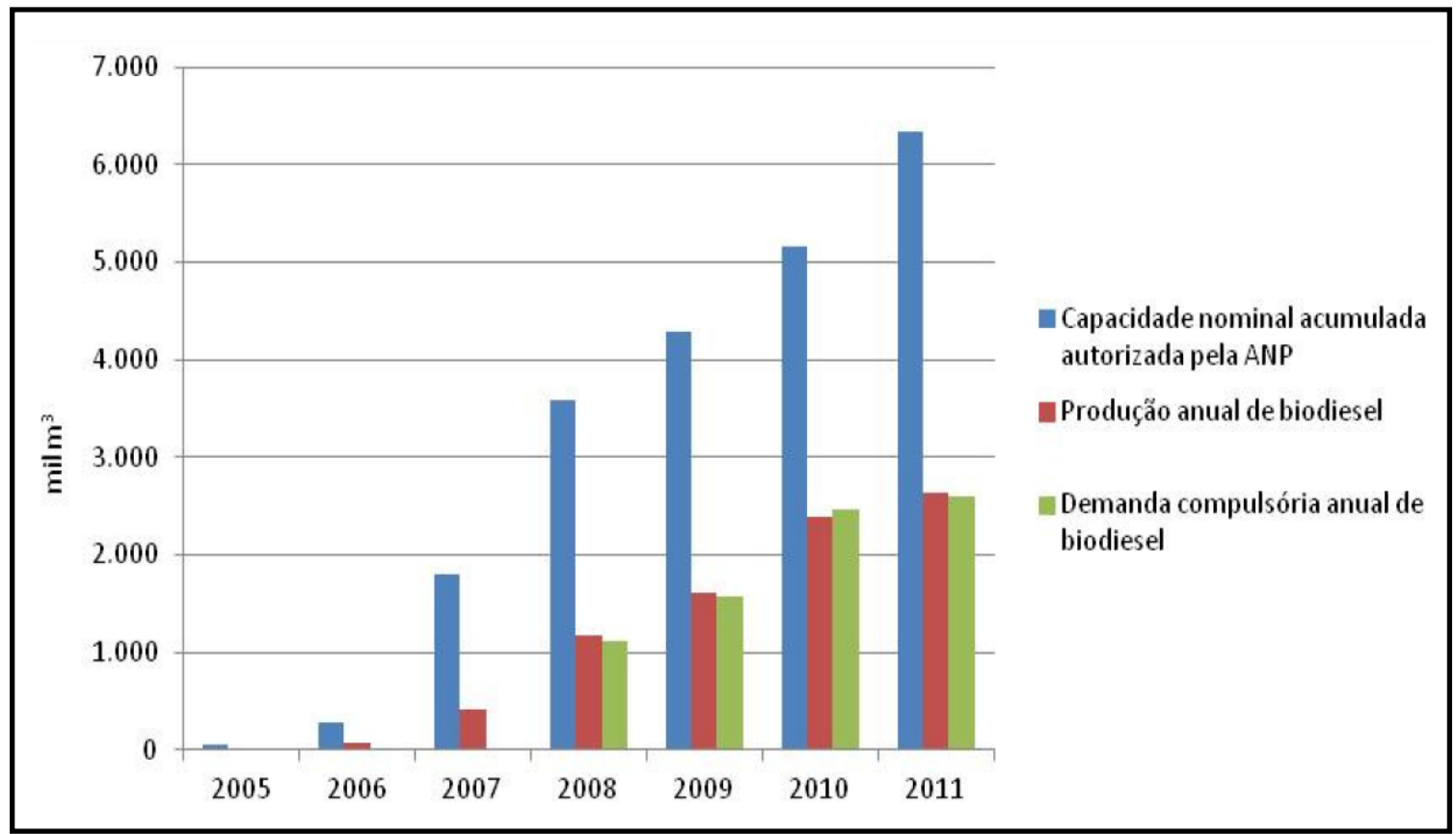

Fonte: ANP - Boletim Mensal do Biodiesel, janeiro de 2012. Disponível em: www.anp.gov.br

Figura 2 - Brasil: evolução anual da produção de biodiesel, demanda compulsória e capacidade nominal autorizada pela ANP entre os anos de 2005 e 2011.

Os dados retratam que a capacidade de produção autorizada pela ANP é muito maior do que a produção real de biodiesel no país e também com relação à demanda compulsória existente atualmente. Outra constatação é que a produção real de biodiesel está no limite da demanda compulsória, o que é ruim para o consumidor, visto que a produção está sempre pressionada pela demanda compulsória e isso pode causar possível falta do produto (biodiesel) no mercado e forte aumento no preço de comercialização do biodiesel, o que, de maneira geral, vai implicar em aumento no preço do óleo diesel, pois todo óleo diesel comercializado no país deve ter 
obrigatoriamente $5 \%$ de biodiesel adicionado e, consequentemente, no aumento em cadeia das demais mercadorias comercializadas no país, devido ao aumento nos custos de transporte, tendo como resultado final o aumento da inflação e crises econômicas de variadas proporções.

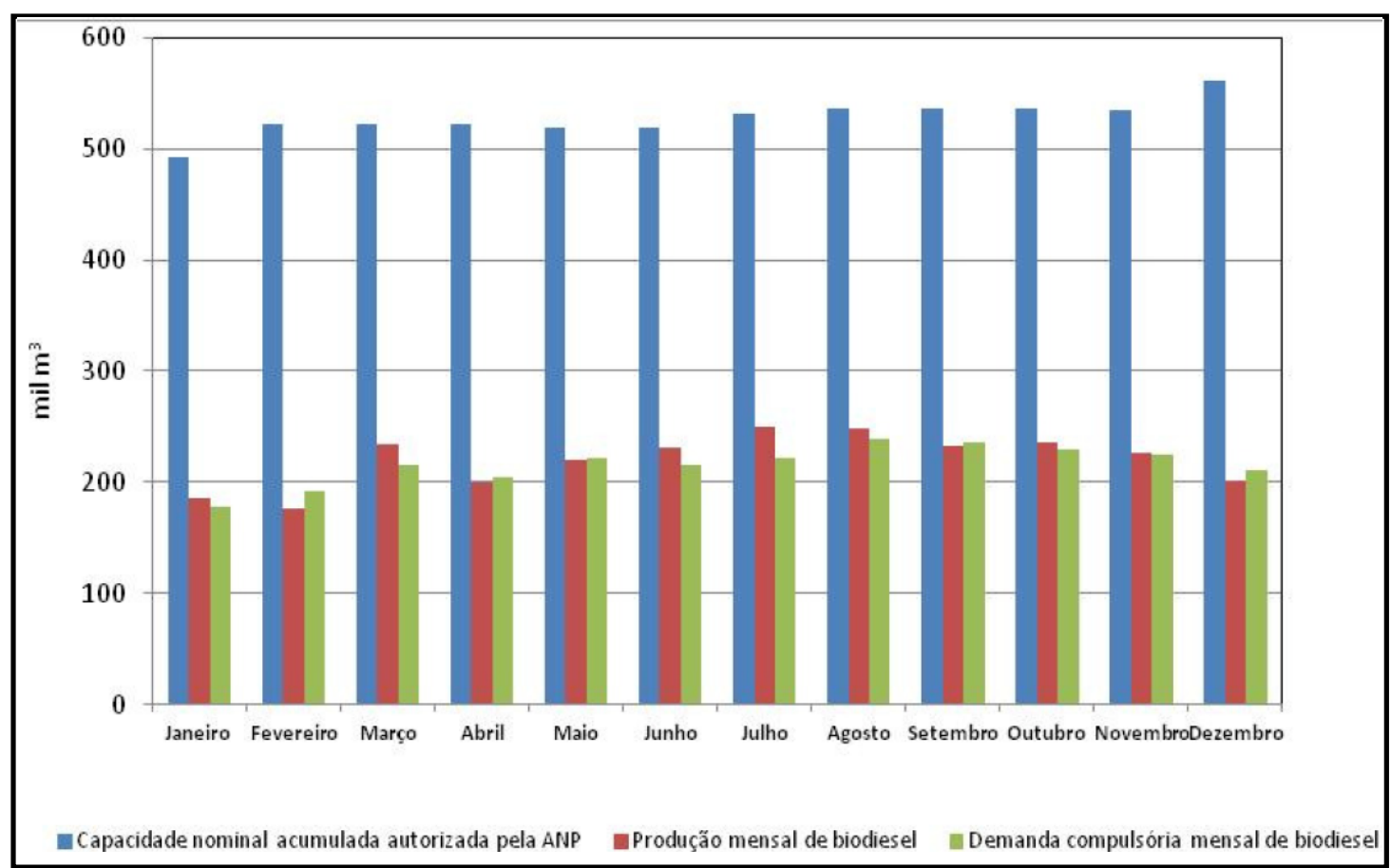

Fonte: ANP - Boletim Mensal do Biodiesel, janeiro de 2012. Disponível em: www.anp.gov.br

Figura 3 - Brasil: evolução mensal da produção de biodiesel, da demanda compulsória e da capacidade nominal autorizada pela ANP de janeiro a dezembro de 2011.

$\mathrm{Na}$ figura 3, verificamos que, nos meses de fevereiro, abril, setembro e novembro do ano de 2011, a demanda compulsória foi maior que a produção real de biodiesel no país, que causou fortes desequilíbrios no mercado nacional de biodiesel, com elevação dos preços de comercialização do combustível nas bombas dos postos de revenda.

De acordo com os dados publicados nos boletins mensais da ANP (janeiro de 2012, dezembro de 2011 e dezembro de 2010), constatamos que existe, no Brasil, uma capacidade autorizada para produção de biodiesel na ordem de $18.977,95 \mathrm{~m}^{3} / \mathrm{dia}$ (mês de referência janeiro de 2012), enquanto, em 2010, a capacidade autorizada era de $16.216,47 \mathrm{~m}^{3} /$ dia (mês de referência dezembro de 2010), registrando um crescimento de $17,02 \%$ na capacidade de produção autorizada pela ANP na comparação entre dezembro de 2010 e janeiro de 2012. 
Com as autorizações de construção de novas plantas produtivas concedidas pela ANP (num total de 10 plantas) e de ampliação de algumas que já existem (num total de 7 plantas) para o ano de 2012, a capacidade autorizada de produção de biodiesel vai crescer um total de $4.627,79 \mathrm{~m}^{3} / \mathrm{dia}$ sendo $4.037,79 \mathrm{~m}^{3} / \mathrm{dia}$ para as novas plantas que serão construídas e $590 \mathrm{~m}^{3} /$ dia para as que serão ampliadas, o que vai corresponder ao crescimento total de $26,04 \%$ na capacidade produtiva autorizada pela ANP com relação a dezembro de 2011.

Esses dados refletem o crescimento da infraestrutura voltada para a produção de biodiesel no Brasil, uma base técnica de produção altamente concentrada nas mãos de grandes empresas, com forte concentração regional e, quase que na totalidade, voltada para trabalhar com matérias-primas oriundas da agricultura capitalista, a exemplo da soja e do caroço do algodão. Essa forte conexão entre a agricultura tecnificada e a logística voltada para a produção de biodiesel fortalece a hegemonia produtiva do grande capital e contribui significativamente para sua expansão de forma espacialmente seletiva e socialmente excludente no campo.

Tabela 1 - Unidades de produção de biodiesel (B100) autorizadas pela ANP entre os anos de 2009 e 2011

\begin{tabular}{c|c|c|c}
\hline Ano & 2009 & 2010 & 2011 \\
\hline Para operação & 63 & 66 & 65 \\
$\begin{array}{c}\text { Para operação e comercialização } \\
\text { Para implantação de unidade de produção }\end{array}$ & 47 & 57 & 60 \\
$\begin{array}{c}\text { Aguardando autorização para } \\
\text { comercialização }\end{array}$ & 20 & 22 & 10 \\
$\begin{array}{c}\text { Produção de biodiesel autorizada em } \\
\text { (m3/dia) }\end{array}$ & 12 & 9 & 5 \\
\hline
\end{tabular}

Fonte: Organizado por SANTOS, J. A. Lobo, com base no Boletim Mensal do Biodiesel, dezembro de 2011. Disponível em: www.anp.gov.br.

Na tabela 1, observamos um crescimento no número de unidades produtivas de biodiesel e no número de autorizações concedidas pela ANP para que novas plantas de produção pudessem produzir e comercializar, assim como para outras serem ampliadas. Identificamos que também houve diversas autorizações para que novas unidades de produção de biodiesel pudessem ser construídas entre os anos de 2009 e 2011, o que possibilitou uma consistente ampliação da capacidade produtiva de biodiesel no país. 
Esse debate é importante, pois a produção de biodiesel está em nítido processo de crescimento no Brasil nos últimos anos. Segundo Osaki e Batalha (2008:09), no ano de 2005, a produção de biodiesel se concentrou nos estados do Pará e Piauí, nos quais foram produzidos $90 \%$ do biodiesel brasileiro. A produção era dominada praticamente por duas grandes empresas, sendo uma do setor de óleo de palma e outra de óleos vegetais gerais (mamona, soja e caroço de algodão).

No ano de 2006, a produção se concentrou nos estados do Piauí, São Paulo e Goiás, que responderam com $86,9 \%$ da produção nacional. Já em 2007, a produção de biodiesel se concentrou nos estados de Goiás, Bahia, Ceará, Rio Grande do Sul, São Paulo e Piauí, que juntos produziram $84 \%$ do biodiesel do ano. A partir do ano de 2008 , a produção foi se deslocando para a região Centro-oeste do Brasil, tendo a soja como principal matéria-prima na produção de biodiesel, principalmente nos estados de Goiás e Mato Grosso. No Nordeste, houve predomínio das oleaginosas, a exemplo da Palma no estado do Piauí, da mamona e do girassol no estado da Bahia, entre outros.

É válido salientar que apesar de muitos agricultores camponeses do estado da Bahia, especialmente do Território de Identidade de Irecê, estarem produzindo e comercializando mamona com a Petrobrás, este produto não vem sendo utilizado como matéria-prima para a produção de biodiesel, pois, devido ao seu alto preço de mercado, a Petrobrás e outras empresas que também adquirem o produto estão destinando a mamona para a produção de outros produtos mais lucrativos junto ao setor da ricinoquímica.

Esse crescimento na produção do biodiesel tem implicado a adoção de novos investimentos públicos e privados, aumento na área plantada de oleaginosas e do consumo, entre outros fatores, o que reforça a necessidade de se aprofundarem as análises acerca dessa temática no país.

Outro elemento preocupante é a forte concentração da produção do biodiesel em poucas empresas o que pode ser embrionariamente caracterizado como a formação de um mercado oligopolizado e altamente seletivo no país, como apontam Osaki e Batalha (2008:09):

Para se ter uma ideia, no ano de 2007 , cerca de $88 \%$ da produção de biodiesel ficou concentrada em quatro empresas, sendo que somente a Brasil Ecodiesel produziu 53\%, seguida pela Granol, Caramuru e Biocapital, com $17 \%, 11 \%$ e $8 \%$ da produção, respectivamente. No ano de 2006, a Brasil Ecodiesel foi a principal produtora de biodiesel, 
seguida da Granol. Juntas responderam por $50 \%$ e $44 \%$, respectivamente, da produção de biodiesel.

Os novos investimentos aliados à infraestrutura produtiva instalada apontam para uma forte concentração regional da produção de biodiesel no Brasil. A concentração, em parte, reflete a organização técnica das plantas produtivas de biodiesel, as quais são construídas tendo como base uma infraestrutura técnica voltada para o processamento de matérias-primas provenientes do latifúndio agrícola, como a soja e outras, produzidas em larga escala em algumas regiões do país, a exemplo das regiões Centro-oeste e Sul. Essa realidade é evidenciada por Pires do Rio (2011:43) quando afirma que:

A estrutura espacial das empresas indica claramente o padrão geográfico do agronegócio: a concentração da localização de usinas nas antigas áreas de agricultura de exportação no estado de São Paulo e nos dois mais recentes eixos de avanço da fronteira agrícola: o primeiro marcado pela BR-163 (Cuiabá-Santarém), que corta o estado de Mato Grosso e o segundo que segue, grosso modo, o traçado da ferrovia Nordeste-Sul, no eixo de desenvolvimento e integração Araguaia-Tocantins, cortando os estados de Goiás e Tocantins para atingir a mais recente fronteira agrícola, localizada na região denominada BAMAPITO. Este padrão reforça, no mercado internacional, a tendência de aprofundamento da divisão territorial do trabalho: Argentina e Brasil especializando-se respectivamente no biodiesel e no etanol.

As principais unidades produtoras de biodiesel estão concentradas nos estados onde o agronegócio possui maior territorialização de sua infraestrutura técnica e econômica e de sua ação política, sobretudo, por meio de uma base agrofundiária altamente tecnificada e calcada na monocultura da soja, na pecuária e na manutenção da grande propriedade como instrumento de poder. 
Tabela 2 - Brasil: Unidades de produção de biodiesel e capacidade de produção em $\mathrm{m}^{3}$ /dia autorizadas pela ANP por Estados, dezembro de 2011

\begin{tabular}{|c|c|c|}
\hline Estado & $\begin{array}{l}\text { Unidades de } \\
\text { produção }\end{array}$ & $\begin{array}{l}\text { Capacidade de Produção autorizada em } \\
\left.\text { ( } \mathrm{m}^{3} / \text { dia }\right)\end{array}$ \\
\hline Acre & - & - \\
\hline Alagoas & - & - \\
\hline Amapá & - & - \\
\hline Bahia & 4 & $1.396,42$ \\
\hline Ceara & 1 & 301,71 \\
\hline Distrito Federal & - & - \\
\hline Espírito Santo & - & - \\
\hline Goiás & 7 & $3.100,70$ \\
\hline Manaus & - & - \\
\hline Maranhão & 1 & 360 \\
\hline Mato Grosso & 20 & $4.215,46$ \\
\hline Mato Grosso do Sul & 3 & 341 \\
\hline Minas Gerais & 5 & 376,11 \\
\hline Pará & 1 & 80 \\
\hline Paraíba & - & - \\
\hline Paraná & 3 & 479 \\
\hline Pernambuco & - & - \\
\hline Piauí & - & - \\
\hline Rio de Janeiro & 1 & 166,7 \\
\hline Rio Grande do Norte & - & - \\
\hline Rio Grande do Sul & 7 & $4.687,33$ \\
\hline Rondônia & 2 & 99 \\
\hline Roraima & - & - \\
\hline Santa Catarina & - & - \\
\hline São Paulo & 8 & $2.678,72$ \\
\hline Sergipe & - & - \\
\hline Tocantins & 2 & 441 \\
\hline Total & 65 & $18.727,95$ \\
\hline
\end{tabular}

Fonte: Organizado por SANTOS, J. A. Lobo, com base nos dados do Boletim Mensal do Biodiesel, dezembro de 2011. Disponível em: www.anp.gov.br

Conforme indicado na tabela 2, o estado de Mato Grosso é o que possui maior número de unidades de produção de biodiesel atualmente no país, sendo um total de 20 unidades de produção $(30,7 \%)$ com uma capacidade total de produção autorizada pela ANP da ordem de 4.215,46 m²/dia de biodiesel (22,5\%). Em segundo lugar, temos o estado de São Paulo com 8 unidades de produção (12,3\%) e 2.678,72 mª dia de capacidade de produção $(14,3 \%)$. Em terceiro, vem os estados de Goiás e do Rio Grande do Sul com 7 unidades de produção cada (10,76\%) e 3.100,70 m³/dia (16.55\%) 
e $4.687,33 \mathrm{~m}^{3} /$ dia $(25,02 \%)$, respectivamente, de capacidade de produção devidamente autorizada pela ANP.

Na região Nordeste, o estado com maior número de unidades de produção é a Bahia com 4 unidades $(6,15 \%)$ e 1.396,42 m³/dia (7,45\%) de capacidade de produção autorizada de biodiesel pela ANP. Na região Norte, aparecem os estados de Rondônia e Tocantins com 2 unidades de produção cada $(3,07 \%)$ e baixíssima capacidade de produção de biodiesel autorizada pela a ANP, sendo $441 \mathrm{~m}^{3} / \mathrm{dia}(2,35 \%)$ e $99 \mathrm{~m}^{3} / \mathrm{dia}^{2}$ $(0,52 \%)$ respectivamente.

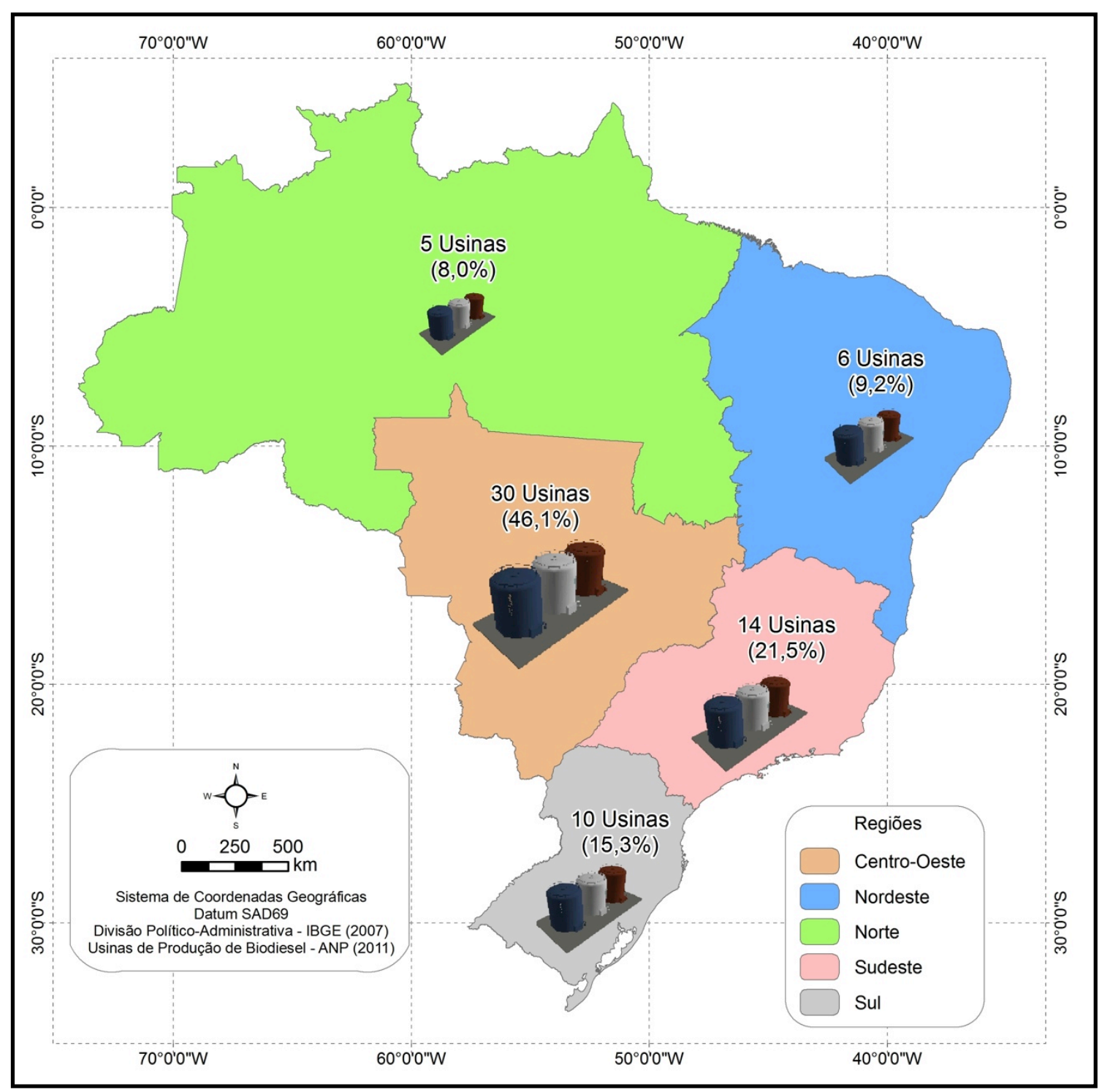

Fonte: Organizado por SANTOS, J. A. Lobo \& SANTOS, Pablo, com base nos dados do Boletim Mensal do Biodiesel, dezembro de 2011. Disponível em: www.anp.gov.br

Figura 4 - Brasil: Espacialização das unidades de produção de biodiesel por região, dezembro de 2011 
$\mathrm{Na}$ distribuição regional, a história não é diferente, pois a concentração da produção de biodiesel em determinadas unidades da federação se reflete na escala regional. Os dados da figura 4 atestam que as regiões Centro-oeste, com 46,1\%; Sudeste, com 21,5\%; e Sul, com 15,3\%, concentram grande parte $(82,9 \%)$ das unidades de produção de biodiesel existentes atualmente no Brasil. Destaque maior para a região Centro-oeste, área fortemente marcada pela expansão da fronteira agrícola com predomínio da monocultura da soja e da pecuária, tendo o latifúndio como modelo de ocupação da terra.

Municípios conhecidos nacionalmente como grandes produtores de soja no Brasil, a exemplo de Sorriso e Rondonópolis, estão, entre outros, numa lista de áreas onde existem diversas unidades de produção de biodiesel, enquanto que muitos estados importantes estão desprovidos de unidades produtoras de biodiesel, a exemplo, de Manaus, Santa Catarina, Pernambuco, dentre outros.

Somente no município de Rondonópolis - MT estão instaladas quatro unidades de produção que são: A Transportadora Caibiense com capacidade produtiva autorizada pela ANP de $100 \mathrm{~m}^{3} /$ dia de biodiesel; a SSIL com capacidade produtiva autorizada de $20 \mathrm{~m}^{3} /$ dia de biodiesel; A RONDOBIO com capacidade produtiva autorizada de 10 $\mathrm{m}^{3} /$ dia de biodiesel; e a ADM com capacidade produtiva autorizada de $1.352 \mathrm{~m}^{3} / \mathrm{dia}$ de biodiesel.

Essas quatro unidades de produção conferem ao município de Rondonópolis uma capacidade produtiva autorizada pela ANP de $1.482 \mathrm{~m}^{3} / \mathrm{dia}$ de biodiesel, ou seja, mais que o dobro do que se tem atualmente autorizado pela ANP para toda região Norte do país que é de apenas $620 \mathrm{~m}^{3} /$ dia. A forte concentração da produção no município de Rondonópolis e sua microrregião é citada por Monteiro e Alves Pinto (2011:128) quando afirmam que:

$\mathrm{Na}$ referida mesorregião, o destaque cabe a microrregião de Rondonópolis, com $53,06 \%$ de capacidade de produção do conjunto mesorregional (...). Em suma, a microrregião de Rondonópolis tem capacidade para produzir mais de $29,5 \%$ do biodiesel mato-grossense, representando pouco mais de $7,46 \%$ da capacidade de produção do país, valores muito superiores aos da capacidade de produção instalada da maioria dos estados brasileiros. Isso significa dizer que além de Mato Grosso, apenas Rio Grande do Sul, Goiás, São Paulo e Bahia possuem capacidade maior de produção de biodiesel que a citada microrregião. 
Verificamos o quanto a infraestrutura da agricultura capitalista, principalmente de produção de soja, está essencialmente enraizada na produção de biodiesel e nas ações estratégicas que PNPB vem desenvolvendo para se territorializar no país.

Tabela 03 Brasil: capacidade de produção de biodiesel $\mathrm{em} \mathrm{m}^{3} /$ dia autorizada pela ANP por região, dezembro de 2011.

\begin{tabular}{c|c|c}
\hline Região & Capacidade de produção $\mathrm{m}^{3} /$ dia autorizada pela ANP & Valores em \% \\
\hline Norte & 620 & 3 \\
Nordeste & $2.058,13$ & 11 \\
Centro-oeste & $7.657,16$ & 41 \\
Sudeste & $3.221,53$ & 17 \\
Sul & $5.166,33$ & 28 \\
\hline Total do Brasil & $18.727,95$ & 100 \\
\hline
\end{tabular}

Fonte: Organizado por SANTOS, J. A. Lobo, com base nos dados do Boletim Mensal do Biodiesel, dezembro de 2011. Disponível em: www.anp.gov.br

Os dados (tabela 3) evidenciam a fraca participação das regiões Norte e Nordeste na produção nacional de biodiesel, o que deixa essas regiões numa posição periférica em relação às demais no PNPB. É a pura elucidação de que o projeto de priorizar as oleaginosas (mamona, palma, dendê, pinhão manso e outras) oriundas principalmente das regiões Norte e Nordeste, via produção camponesa, está naufragando, sucumbindo diante dos interesses da produção capitalista que, essencialmente, se fundamentam na concentração da produção, da circulação, da comercialização e dos ganhos, bem como no aumento crescente do lucro como mostra Karl Marx (1989:172):

Enquanto a apropriação crescente da riqueza abstrata for o único motivo que determina suas operações, funcionará ele como capitalista, ou como capital personificado, dotado de vontade e consciência. Nunca se deve considerar o valor-de-uso objetivo imediato do capitalista. Tampouco o lucro isolado, mas o interminável processo de obter lucros. Esse impulso de enriquecimento absoluto, essa caça apaixonada ao valor é comum ao capitalista [...].

A busca a qualquer preço pelo lucro subverte condutas, corrompe ações e direciona políticas públicas de acordo com os interesses do capital e/ou do capitalista. $\mathrm{O}$ que vale nessa lógica é a concentração da riqueza por meio da exploração direta e indireta do trabalho. Nesse sentido, a análise crítica tem mostrado que o PNPB está mergulhado nessa teia de relações sociais controladas por agentes hegemônicos do 
capital. Um dos indícios desse controle do capital é a forte presença de matérias-primas oriundas da agricultura capitalista na produção de biodiesel em contradição com a utilização de matérias-primas oriundas da agricultura camponesa.

\section{Agentes hegemônicos e monopólio capitalista na produção de biodiesel}

Ressaltamos que, além da concentração regional da produção de biodiesel, também existe um forte controle da produção, ou seja, um conjunto formado por apenas 12 grandes empresas de capital nacional e internacional, distribuídas por 10 estados brasileiros, foram responsáveis por $80,8 \%$ da produção nacional de biodiesel, como se evidencia na tabela 4.

Tabela 4 - Brasil: principais empresas produtoras de biodiesel no ano de 2011

\begin{tabular}{c|c|c}
\hline Unidades produtoras de biodiesel & Estado & $\begin{array}{c}\text { Total acumulado em 2011 } \\
\mathrm{em} \mathrm{m} / \mathrm{d}\end{array}$ \\
\hline Granol & RS / GO & 364.670 \\
Caramuru - São Simão / Ipameri & GO & 227.251 \\
Oleoplan & RS & 219.908 \\
Pbio & BA / MG / CE & 216.682 \\
BSbios & RS / PR & 189.744 \\
Brasil Ecodiesel & BA/MA/RS/TO & 176.821 \\
ADM & MT & 146.765 \\
Olfar & RS & 119.399 \\
Fiagril & MT & 118.934 \\
Biocapital & SP & 104.301 \\
JBS - Lins & SP & 97.215 \\
Camera & RS & 92.758 \\
\hline Total & \multicolumn{2}{c}{} \\
\hline
\end{tabular}

Fonte: Organizado por SANTOS, J. A. Lobo, com base nos dados do Boletim Mensal do Biodiesel, dezembro de 2011. Disponível em: www.anp.gov.br

A Granol, com unidades de produção de biodiesel nos estados do Rio Grande do Sul e de Goiás, foi a maior produtora de biodiesel do país no ano de 2011, seguida pela Caramuru, Oleoplan e pela Pbio (Petrobras Biodiesel). Juntas, as quatro primeiras empresas em produção de biodiesel responderam por um total de $1.028 .511 \mathrm{~m}^{3} / \mathrm{dia}$, o que equivaleu a $40 \%$ da produção nacional que foi de $2.567 .706 \mathrm{~m}^{3} /$ dia. 
Essas informações (tabela 4) demonstram a existência de contradições entre o discurso e a prática do PNPB, uma vez que, na teoria, o Programa é colocado como fruto de uma política pública voltada para a soberania energética e para o desenvolvimento social, sendo que, na prática, vem se revelando como um conjunto de ações que estão gerando muito mais oportunidades para a territorialização concentrada do capital no campo e na produção industrial. Essa forma de estabelecer relações de poder no território está espacialmente evidente na concentrada distribuição regional da produção, no total predomínio das grandes empresas nacionais e multinacionais na produção/comercialização do biodiesel e no império da soja como matéria-prima principal do biodiesel brasileiro.

Com um olhar atento, percebemos que o PNPB, em muitos momentos, serve mais ao campo ideológico do marketing internacional, visando projetar a imagem do Brasil como um país que está na vanguarda da produção de energias limpas e renováveis do que, de fato, se colocando como um Programa voltado para o desenvolvimento social de forma horizontalizada, sobretudo, com a inclusão autônoma do campesinato em sua estrutura produtiva e de gestão. Nesse ponto, concordamos com a Júlia Adão Bernardes (2011:66) quando afirma que:

Não resta dúvida que o programa vem tendo sucesso na tentativa de construção de uma imagem para projetar o país no mundo como produtor de energia limpa que gera benefícios globais. Quanto ao papel da agricultura familiar e sua inclusão social, que deveria contribuir com significativa oferta de matéria-prima, as respostas foram menos satisfatórias. No conjunto das políticas energéticas, o diferencial do biodiesel é exatamente a inserção econômica e social dos pequenos agricultores, meta que está longe de ser alcançada.

Essas contradições evidenciam que, na sua estrutura, o PNPB vem se revelando muito mais como um apêndice do modo capitalista de produção para expandir atividades no campo por meio da criação de novos fluxos de capital do que priorizando a inclusão dos camponeses no projeto nacional de desenvolvimento de novas fontes energéticas. Grandes empresas estão tendo muito mais participação do que outros segmentos da sociedade no PNPB, pois "as dez principais empresas produtoras de biodiesel no Brasil foram responsáveis pela produção de $81 \%$ do biodiesel em 2010 . Ou seja, há no mercado produtor deste agrocombustível uma forte concentração" (OLIVEIRA, 2011:55). 
Essa forte junção entre o PNPB, a agricultura capitalista e as grandes empresas está se materializando em específicos fluxos de capital que mantêm relações sociais fundamentadas no modelo produtivo de intensa exploração do trabalho no campo, em que a intensa presença técnica é travestida de moderna e ideologicamente mergulhada numa modernidade global que se fundamenta nos ritmos desiguais do desenvolvimento econômico e social, ou seja:

(...) A modernidade, porém, não é feita pelo encontro homogeneizante da diversidade do homem, como sugere a concepção de globalização. É constituída, ainda, pelos ritmos desiguais do desenvolvimento econômico e social, pelo acelerado avanço tecnológico, pela acelerada e desproporcional acumulação de capital, pela imensa e crescente miséria globalizada, dos que têm fome e sede de justiça, de trabalho, de sonho, de alegria. Fome e sede de realização democrática das promessas da modernidade, do que ela é para alguns e, ao mesmo tempo, apenas parece ser para todos. (MARTINS, 2010:19)

O que nos leva a crer, com base nos dados analisados, que o PNPB também está se territorializando nas diversas partes do país por meio de instrumentos que historicamente estiveram conectados com a produção de espaços desiguais e de pouca ou quase nenhuma participação da coletividade social. Esses espaços desiguais contribuem diretamente para perpetuar o modelo de modernidade criticado por Martins (2010).

A forma como o Programa vem se instrumentalizando, sobretudo para atender as metas produtivas de biodiesel estabelecidas no marco regulatório, em nada difere de outras ações desenvolvidas no Brasil que ao final acabaram de forma direta e indireta contribuindo para viabilizar a territorialização do grande capital no campo, a concentração de terras, a monopolização dos recursos naturais e a expropriação da renda da terra camponesa, a qual, na prática, se consolida com exploração de trabalho, como mostra Karl Marx (2008:846) quando afirma que:

Toda renda fundiária é mais-valia, produto do trabalho excedente. $\mathrm{Na}$ forma menos desenvolvida, é diretamente produto excedente, a renda natural. Mas, no modo capitalista de produção, a renda fundiária é sempre sobra acima do lucro, acima da fração do valor das mercadorias, a qual por sua vez consiste em mais-valia (trabalho excedente).

Outro fator que devemos levar em questão é que a produção de biodiesel poderá em breve atender ao mercado internacional, o que acarretará problemas de 
encarecimento do produto e desabastecimento do mercado interno, como nos alerta Oliveira (2011:59) ao afirmar que:

[...] a partir do momento, como ocorreu na atualidade com o etanol e o açúcar, que existe demanda mundial, o setor passará a exportar o biodiesel. Isto quer dizer que haverá redução da oferta no mercado interno, com consequente desabastecimento.

A questão é que, por hora, o biodiesel ainda está sendo tratado no âmbito de uma política pública estratégica ao desenvolvimento de novas fontes energéticas no país, porém, com a constante presença do grande capital, que cada vez mais oligopoliza o mercado e concentra espacialmente as unidades de produção, o biodiesel tende a se tornar, em um curto período, uma commodity, por mais que Oliveira (2011:59) afirme ainda não o ser: "Hoje esta questão não aparece devido ao biodiesel estar relacionado a políticas nacionais de segurança energética, portanto, não se trata ainda de uma commodity".

\section{Considerações finais}

O que podemos dizer é que no formato em que está sendo implantado, o PNPB está mergulhando numa lógica de competitividade, consumo e confusão dos interesses, comandada por regras de um mundo globalizado para atender as demandas dos fluxos de capital. É a lógica expansionista e excludente do modo capitalista de produção se sobrepondo aos interesses da coletividade social. O pior é que as próprias políticas públicas que, em tese, deveriam garantir equidade social são utilizadas como força motriz para mover a engrenagem do monopólio da produção capitalista e da oligopolização do mercado.

Ponderamos, então, que, no plano nacional, a infraestrutura da agricultura capitalista e de grandes empresas ligadas a outros setores está dominando a produção de biodiesel no Brasil. Assim, nesse contexto, verificamos, em resumo, que:

- A soja, como matéria-prima, responde atualmente por $71,13 \%$ da produção de biodiesel, a gordura bovina por $18,66 \%$, e o óleo de algodão por 4,69\%. Juntos, esses três produtos (soja, algodão e gordura bovina) são responsáveis por 94,48\% do biodiesel produzido no país.

- Houve a formação de um mercado nacional de produção e comercialização de biodiesel extremamente oligopolizado, pois apenas 12 grandes empresas respondem atualmente por $80,8 \%$ da produção e da comercialização do biodiesel 
no país; sendo válido destacar que, dessas empresas, a Granol, com unidades de produção de biodiesel nos estados do Rio Grande do Sul e de Goiás, foi a maior produtora de biodiesel do país no ano de 2011, seguida pela Caramuru, Oleoplan e pela PETROBRÁS Biodiesel (Pbio). Juntas, as quatro primeiras empresas em produção de biodiesel, responderam por um total de $1.028 .511 \mathrm{~m}^{3} / \mathrm{dia}$, o que equivaleu a $40 \%$ da produção nacional, que foi de $2.567 .706 \mathrm{~m}^{3} /$ dia.

- A espacialização da produção se deu de forma concentrada, pois $46,1 \%$ das unidades de produção estão localizadas na região Centro-oeste, $21,5 \%$ na região Sudeste, $15,3 \%$ na região Sul. Juntas essas regiões concentram 82,9\% das unidades de produção de biodiesel existentes atualmente no Brasil. Há um destaque maior para a região Centro-oeste, área fortemente marcada pela expansão da fronteira agrícola, com predomínio da monocultura da soja, da pecuária e do latifúndio como modelo de ocupação da terra. Essa estrutura produtiva revela contradições inerentes à ampliação de capital no seio do PNPB, cuja organização acompanha a logística da agricultura capitalista em escala nacional.

- Os objetivos institucionais e o marco regulatório do Programa apresentam ideologicamente uma proposta voltada para a superação dos antagonismos de classes, propondo criar novas relações socioprodutivas fundamentadas na sustentabilidade social, mas, na prática, a realidade espacial e territorial vem mostrando que o PNPB tem se revelado em mais um instrumento do capital para a geração de novos atalhos para a sua reprodução e de densa rede aos novos fluxos de capital.

Contrariando os caminhos trilhados, espera-se que o PNPB não seja somente mais um programa voltado para garantir a existência de novos fluxos de capital no espaço de forma excludente, concentrada e sob rígido controle de grupos hegemônicos. O PNPB, como fruto de políticas públicas orquestradas pelo Estado, deve se pautar por prioridades que levem em consideração a busca pela soberania energética do país, a democratização do acesso aos biocombustíveis, a inclusão participativa das mais diversas camadas sociais na operacionalização e gestão do Programa, a integração com outros programas de cunho social e a plena sintonia com uma política estrutural de redução das desigualdades no país. 


\section{Referências}

ABRAMOVAY, R.; MAGALHÃES, R. O acesso dos agricultores familiares aos mercados de biodiesel: parcerias entre empresas e movimentos sociais. São Paulo: FEA-USP/PLURAL CONSULTORIAS, 2007 (relatório de pesquisa).

AGÊNCIA NACIONAL DE PETRÓLEO, GÁS NATURAL E BIOCOMBUSTÍVEIS (ANP). Biocombustíveis. Rio de Janeiro, 2012. Acessado pelo autor em fevereiro de 2012. Disponível em: www.anp.gov.br.

AGÊNCIA NACIONAL DE PETRÓLEO, GÁS NATURAL E BIOCOMBUSTÍVEIS (ANP). Boletim mensal do biodiesel. Rio de Janeiro, ano: janeiro de 2012. Acessado pelo autor em fevereiro de 2012. Disponível em: www.anp.gov.br.

AGÊNCIA NACIONAL DE PETRÓLEO, GÁS NATURAL E BIOCOMBUSTÍVEIS (ANP). Boletim mensal do biodiesel. Rio de Janeiro, ano: dezembro de 2011. Acessado pelo autor em fevereiro de 2012. Disponível em: www.anp.gov.br.

AGÊNCIA NACIONAL DE PETRÓLEO, GÁS NATURAL E BIOCOMBUSTÍVEIS (ANP). Superintendência de Abastecimento (SAB): relatório de movimentação de produto - 08/11/2011. Acessado pelo autor em fevereiro de 2012. Disponível em: www.anp.gov.br.

BERNARDES, J. A. Políticas públicas, selo combustível social e território usado. In: BERNARDES, J. Adão; ARACRI, L. A. dos Santos (Org.). Novas fronteiras do biodiesel na Amazônia: limites e desafios da incorporação da pequena produção agrícola. Rio de Janeiro, Arquimedes Edições, 2011. p. 65 - 76.

BRAY, S. C.; FEREIRA, E. R.; RUAS, G. D. G.. As políticas da indústria canavieira e as políticas do Proálcool no Brasil. Marília, Unesp - Marília - Publicações, 2000.

CARTILHA BIODIESEL. Biodiesel. O novo combustível do Brasil: Programa nacional de produção e uso do biodiesel. Brasília, 2004. Disponível em $<$ http://www.biodiesel.gov.br $>$. Acessado pelo autor em: 25 de novembro de 2008.

ELIAS, D. Prefácio. In: BERNARDES, J. Adão; ARACRI, L. A. dos Santos (Org.). Novas fronteiras do biodiesel na Amazônia: limites e desafios da incorporação da pequena produção agrícola. Rio de Janeiro, Arquimedes Edições, 2011. p. 11 $-22$.

MARTINS, J. de S. A sociabilidade do homem simples: cotidiano e história na modernidade anômala. 2 ed., São Paulo: Contexto, 2010.

MARX, K. O capital: critica da economia política, livro terceiro: o processo global de produção capitalista, volume VI, Rio de Janeiro, Civilização Brasileira, 2008.

MARX, K. O capital: critica da economia política, livro 1 - o processo de produção do capital. v. 1, 13. a edição, Rio de Janeiro, Bertrand Brasil S.A., 1989. 
MONTEIRO, J. L. G.; ALVES PINTO, Anderson. O biodiesel e o selo combustível social: dificuldades de implementação em Mato Grosso. In: BERNARDES, J. Adão; ARACRI, L. A. dos Santos (Org.). Novas fronteiras do biodiesel na Amazônia: limites e desafios da incorporação da pequena produção agrícola. Rio de Janeiro, Arquimedes Edições, 2011. p. 127 - 144.

MINISTÉRIO DO DESENVOLVIMENTO AGRÁRIO. Secretaria de Agricultura Familiar. Biodiesel. Brasília, 2008. Disponível em: <http://www.mda.gov.br $>$. Acessado pelo autor em: 23 de Nov. de 2010.

Secretaria da Agricultura Familiar: legislação - programas - biodiesel. Decreto $\mathrm{n}^{\circ} 6.458$ de 14 de maio de 2008. Acessado pelo autor em fevereiro de 2012.

em: http://www.mda.gov.br/portal/saf/programas/biodiesel/2290882

Secretaria da Agricultura Familiar: legislação - programas - biodiesel. Decreto $n^{0} 5.297$ de 6 de dezembro de 2004. Acessado pelo autor em fevereiro de 2012.2 Disponível em: http://www.mda.gov.br/portal/saf/programas/biodiesel/2290882

MINISTÉRIO DE CIÊNCIA E TECNOLOGIA (MCT). O Programa. O programa nacional de produção e uso de biodiesel. Brasília, jul. 2005. Disponível em: $<$ http://www.biodiesel.gov.br>. Acesso em: 25 de novembro de 2008, p. 01.

OLIVEIRA, A. U. de. Os agrocombustíveis e os dilemas da agricultura camponesa e familiar. In: BERNARDES, J. Adão; ARACRI, L. A. dos Santos (Org.). Novas fronteiras do biodiesel na Amazônia: limites e desafios da incorporação da pequena produção agrícola. Rio de Janeiro, Arquimedes Edições, 2011. p. 47 64.

OSAKI, M; BATALHA, M. O. Produção de biodiesel e óleo vegetal no Brasil: realidade e desafio. São Carlos - SP, GEPAI/DEP/UFSCAR, 2008.

PRADO, E. A.; ZAN, R. A..; GOLFETTO, D. C.; SCHWADE, V. D. Biodiesel: um tema para uma aprendizagem efetiva. Anais do XXXIV COBENGE, Passo Fundo: Ed. Universidade de Passo Fundo, Setembro de 2006. p. 9.203 - 9.215

PIRES DO RIO, G. A. Escalas de política energética: o programa nacional de biodiesel. In: BERNARDES, J. Adão; ARACRI, L. A. dos Santos (Org.). Novas fronteiras do biodiesel na Amazônia: limites e desafios da incorporação da pequena produção agrícola. Rio de Janeiro, Arquimedes Edições, 2011. p. 27 46.

VASCONCELLOS, G. F.; VIDAL, J. W.B. Poder dos trópicos: meditação sobre a alienação energética na cultura brasileira. São Paulo, Casa Amarela, 2004. 